J. Clin. Chem. Clin. Biochem.

Vol. 25, 1987, pp. 253-259

(C) 1987 Walter de Gruyter \& Co.

Berlin - New York

\title{
Simultaneous Determination of Chloride, Sulphate, Orthophosphate and Organic Anions in Human Urine by Capillary Isotachophoresis
}

\author{
By P. Pei and D. J. Vonderschmitt \\ Central Laboratory of Clinical Chemistry, University Hospital, Zurich, Switzerland
}

(Received September 24, 1986/January 26, 1987)

Summary: The principle of isotachophoresis has been used to develop a simple, specific and sensitive analytical method for the determination of anions in untreated urine. Isotachophoretic separation of anions in the presence of complex-forming counter ions (e.g. $\mathrm{Cd}^{2+}$ ) enables the quantitative separation and determination of chloride, sulphate and orthophosphate in the same sample and the less accurate measurement of the concentrations of citrate, formate, acetate, hippurate, benzoate and glucuronate. The mean deviation from $100 \%$ recovery of chloride, sulphate and orthophosphate added to urine samples is $3.1 \%$. The proposed method shows good agreement with chemical (routine) methods.

\section{Introduction}

Human urine contains a number of anionic constituents of which only chloride and phosphate are determined routinely. As a result, the concentrations of these ions, in both healthy and sick individuals, are well documented. Much less attention has been paid to other anions such as sulphate. Inorganic urinary sulphate determinations are of interest for the evaluation of endogenous acid production (1) and in the experimental evaluation of the acid-excreting potential of the kidney $(2-3)$. Urinary excretion of sulphate is low in subjects on a protein-deficient diet and in patients with the rare hereditary disorders of sulphite oxidase deficiency, but is high in diabetic patients.

A suitable method for the determination of anions is capillary isotachophoresis. It is a high resolving electrophoretic separation method that has been described by several authors (4-6). Practical applications of the method for the determination of urinary oxalate and citrate having recently been published $(7-9)$. For the determination of lactate in plasma a good correlation between isotachophoresis and an enzymatic test was found for both normal and ele- vated values (10). Quantitative determination of ascorbic acid in leukocytes in the urine of healthy persons has been reported (11) and Mikkers et al. analysed uraemic blood samples for ionic substances, using isotachophoresis (12).

One advantage of the technique, which is well illustrated by the published applications, is that it permits a direct physical measurement and affords high specificity. It offers the possibility of multicomponent analysis of inorganic and organic ions.

Ion chromatography is often regarded as a more elegant alternative method to isotachophoresis. It suffers, however, from a number of disadvantages and has mainly been used for the analysis of waters of different origin $(13,14)$. Only a few applications in clinical chemistry have been reported $(15-17)$. The main disadvantages are the rapid deterioration of the separation efficiency due to biological material containing proteins and lipids, and the needs of a suppressor to cancel the conductivity of the eluent. Isotachophoresis, in contrast, does not depend on a carrier material and the potential gradient detector is an universal detector which does not depend on special properties of the separating medium. 
We present a method for the simultaneous determination of chloride, sulphate and orthophosphate in a few microliters of urine. The concentrations of these ions were determined in patient samples and the reproducibility, accuracy, linearity and correlation with currently used methods were examined.

\section{Materials and Methods}

\section{Materials}

All chemicals were of highest commercially available quality. A reference mixture of nine anions was prepared, containing sodium chloride, sodium sulphate, monosodium dihydrogen phosphate, citric acid, sodium glucuronate, hippuric acid, benzoic acid and sodium acetate, the concentration of each compound being $1 \mathrm{mmol} / \mathrm{l}$. Urines ( $24 \mathrm{~h}$ specimens) were collected without additives in plastic bottles. Each specimen was kept frozen until used. After a 2- or 3-fold dilution with distilled water samples were directly injected into the isotachophoretic analyser.

\section{Apparatus}

A Shimadzu IP-2A isotachophoretic analyser, equipped with a potential gradient detector, a UV-detector, a $300 \mathrm{~mm}$ FEP capillary (0.5 mm I. D.) and a $40 \mathrm{~mm}$ PTFE capillary (1.0. $\mathrm{mm}$ I. D.) as the pre-column was used for the separation and determination of the standard and sample solutions. The apparatus was also equipped with a current program. Microliter samples were injected with a Hamilton syringe. The isotachophoresis patterns for these samples were recorded at chart speeds of 1.0 and $2.0 \mathrm{~cm} / \mathrm{min}$. The data processor used was the isotachopac I-E 1B (Shimadzu Corporation Kyoto, Japan), which calculated the intervals between peaks (zone length), potential gradient values and time between two arbitrary potential values.

\section{Operational conditions}

Sample: Standard solution or diluted urine

Leading electrolyte:

$2 \mathrm{mmol} / 1 \mathrm{HNO}_{3}, 3 \mathrm{mmol} / \mathrm{l} \mathrm{Cd}\left(\mathrm{NO}_{3}\right)_{2}, 1.5 \mathrm{mmol} / 1 \beta$ =alanine, $0.04 \%$ hydroxypropylmethylcellulose, $\mathrm{pH} 3.0$

Terminating electrolyte:

$20 \mathrm{mmol} / \mathrm{l}$ caproic acid (or benzoic acid)

Migration tube:

$1.0 \mathrm{~mm} \mathrm{I.D.} \times 40 \mathrm{~mm}+0.5 \mathrm{~mm} \mathrm{I.D.} \times 300 \mathrm{~mm}$

Migration current:

$$
300 \mu \mathrm{A}(8 \mathrm{~min}) \rightarrow 100 \mu \mathrm{A}
$$

Bath temperature:

$$
20^{\circ} \mathrm{C}
$$

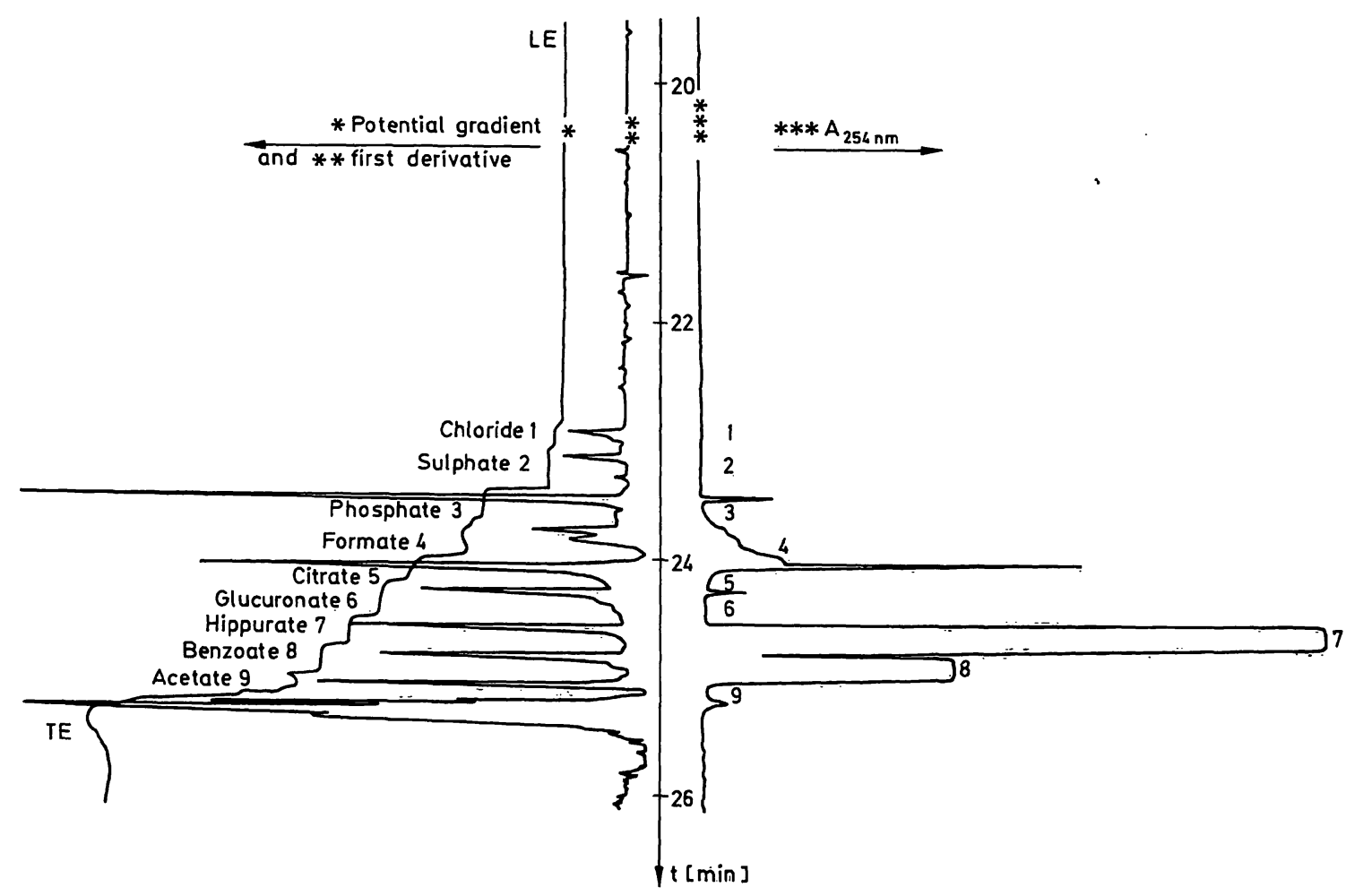

Fig. 1. Isotachopherogram of a standard mixture of nine anions. Volume injected: $5.0 \mu \mathrm{l}(1 \mathrm{mmol} / \mathrm{l}$ of each component) Potential gradient (arbitrary units)

UV absorbance, $254 \mathrm{~nm}$ (arbitrary units)

$\mathrm{LE}=$ Leading electrolyte

$\mathrm{TE}=$ Terminating electrolyte 


\section{Results}

\section{Anions}

The isotachopherogram of the anion reference mixture showing the component characteristic zone heights of nine anionic compounds is presented in figure 1. Figure 2 shows a typical example of the resulting isotachopherogram of a urine sample. With a constant sample volume the concentration of the various anionic compounds were determined from the corresponding zone length by interpolation from the standard curve. The standard curves of chloride, sulphate and orthophosphate were linear over the whole range used in these experiments $(r>0.9997)$ and no duplicate measurements were made.

\section{Procedure}

Urine was routinely diluted 2 or 3 times with distilled water, and $1.0 \mu \mathrm{l}$ was injected into the isotachophoretic analyser without further pretreatment. During the separation process a constant current was applied. The potential gradient of the separated ion zones was recorded. For an easy and more accurate measurement of zone lengths the signal of the potential gra- dient was differentiated. This was registered on the same recording. The nature and concentration of each anionic compound present in urine was determined by comparison with the isotachophoretic pattern of appropriate standard compound(s).

\section{Reproducibility}

A series of 8 to 10 assays for chloride, sulphate and orthophosphate was performed by the described technique on 4 pooled urine samples within the same day. The resulting data are shown in table 1.

\section{Calibration and quantification}

Calibration curves were established for chloride, sulphate and phosphate standards dissolved in both water and pooled urine. They were constructed by plotting the zone length (seconds) against the amounts (nanomoles) of the standard solution of chloride, sulphate and orthophosphate injected. The relationships between amounts $(x)$ of components and the zone length $(y)$ obtained from the isotachopherograms are presented in table 2 .

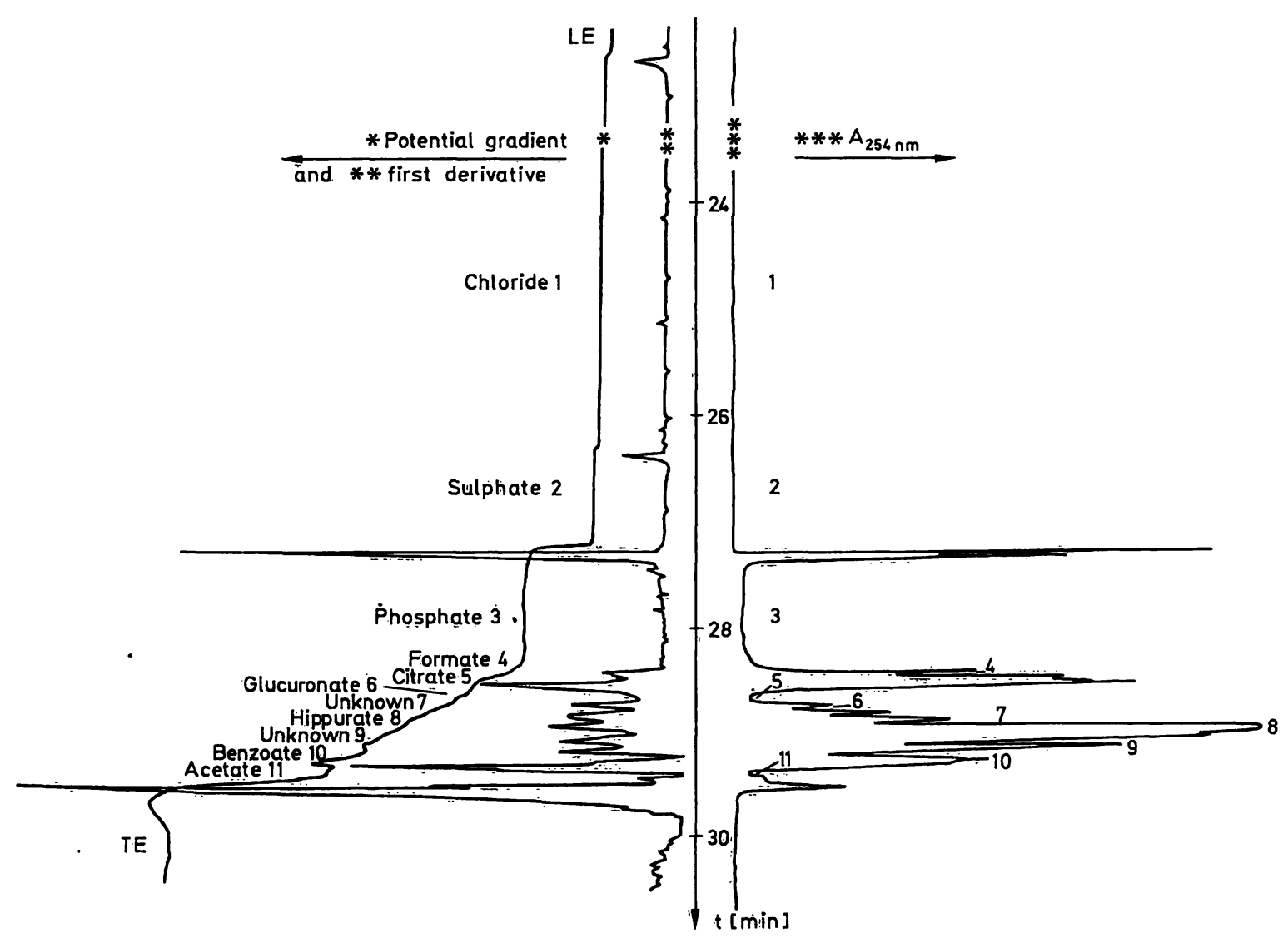

Fig. 2. Isotachopherogram of urine. Volume injected: $1.0 \mu \mathrm{l}$. Components identified are indicated in figure 1. 
Tab. 1. Reproducibility of analysis of urinary chloride, sulphate and orthophosphate. ( $1 \mu$ of the pooled urine samples were analysed repeatedly)

\begin{tabular}{|c|c|c|c|c|c|c|c|c|c|}
\hline Pooled urine & $\begin{array}{l}\text { Chloride } \\
\overline{\mathbf{x}}\end{array}$ & S.D. & C. V. & $\begin{array}{l}\text { Sulphate } \\
\overline{\mathbf{x}}\end{array}$ & S.D. & C. V. & $\begin{array}{l}\text { Ortho-Ph } \\
\overline{\mathrm{x}}\end{array}$ & $\begin{array}{l}\text { osphate } \\
\text { S. D. }\end{array}$ & C. V. \\
\hline $\begin{array}{l}\text { Pool A }(n=8) \\
\text { Pool B }(n=10) \\
\text { Pool C }(n=10) \\
\text { Pool D }(n=10)\end{array}$ & $\begin{array}{l}255 \\
88.1 \\
103 \\
102\end{array}$ & $\begin{array}{l}5.1 \\
5.4 \\
2.7 \\
3.6\end{array}$ & $\begin{array}{l}2.0 \\
6.1 \\
2.6 \\
3.5\end{array}$ & $\begin{array}{r}11.3 \\
12.1 \\
13.9 \\
9.0\end{array}$ & $\begin{array}{l}0.19 \\
0.21 \\
0.48 \\
0.14\end{array}$ & $\begin{array}{l}1.7 \\
1.7 \\
3.5 \\
1.6\end{array}$ & $\begin{array}{l}15.6 \\
17.2 \\
16.4 \\
10.2\end{array}$ & $\begin{array}{l}0.17 \\
1.08 \\
1.07 \\
0.20\end{array}$ & $\begin{array}{l}1.1 \\
6.3 \\
6.5 \\
2.0\end{array}$ \\
\hline
\end{tabular}

$\overline{\mathrm{x}}=$ Mean concentration $(\mathrm{mmol} / \mathrm{l})$,

$\mathrm{SD}=$ Standard deviation $(\mathrm{mmol} / \mathrm{l})$

$\mathrm{CV}=$ Coefficient of variation $(\%)$
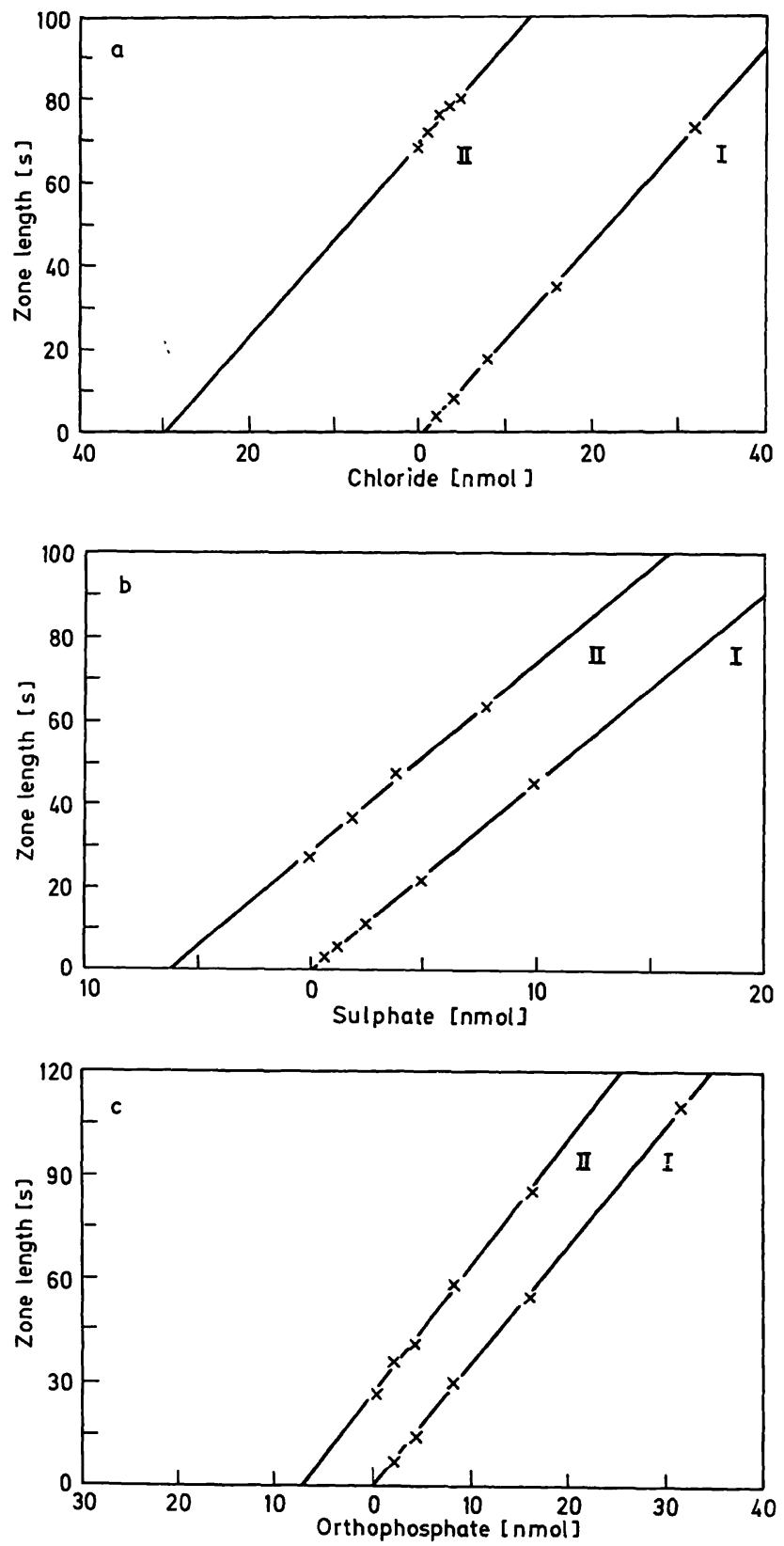

Fig. 3. Linearity of relation between zone length and added amount in water or pooled urine.
(a) chloride
(b) sulphate
(c) orthophosphate.
I = calibration curve of standard solution
II = calibration curve after standard addition in pooled urine.

Tab. 2. Calibration curves of chloride, sulphate and orthophosphate

\begin{tabular}{lll}
\hline Component & $\begin{array}{l}\text { Calibration curve } \\
\text { of standard solution }\end{array}$ & $\begin{array}{l}\text { Calibration curve } \\
\text { after standard addition } \\
\text { in pooled urine }\end{array}$ \\
\hline Chloride & $\begin{array}{l}\mathrm{y}=2.35 \mathrm{x}-1.11 \\
\mathrm{r}=1.000\end{array}$ & $\begin{array}{l}\mathrm{y}=2.36 \mathrm{x}+69.84 \\
\mathrm{r}=0.987\end{array}$ \\
Sulphate & $\mathrm{y}=4.51 \mathrm{x}-0.48$ & $\begin{array}{l}\mathrm{y}=4.51 \mathrm{x}+28.03 \\
\mathrm{r}=1.000\end{array}$ \\
$\begin{array}{ll}\mathrm{r}=1.000 \\
\text { Orthophos- }\end{array}$ & $\begin{array}{l}\mathrm{y}=3.45 \mathrm{x}+0.44 \\
\mathrm{r}=1.000\end{array}$ & $\begin{array}{l}\mathrm{y}=3.65 \mathrm{x}+27.51 \\
\mathrm{r}=0.999\end{array}$ \\
\hline
\end{tabular}

The calibration curves for the three components were linear up to $40 \mathrm{nmol}$ for chloride, $20 \mathrm{nmol}$ for sulphate and $30 \mathrm{nmol}$ for orthophosphate with a sample volume of $1 \mu$ l. Correlation coefficients ranged from 0.987 to 1.000 . Every sample was tested in triplicate in order to obtain the calibration curves. The imprecision was very low. The coefficients of variation were $1.73 \%, 2.42 \%$ and $1.98 \%$ for chloride, sulphate and orthophosphate, respectively.

\section{Recovery}

Different amounts of sodium chloride, sodium sulphate and monosodium dihydrogen-phosphate were added to a pooled urine sample. Data obtained are summarized in table 3.

\section{Method comparison}

The proposed method was compared directly with alternative methods. Figures 4 to 6 show the correlation between isotachophoretic determinations and routine methods for chloride, sulphate and phosphate. The corresponding techniques were coulometric titration (18), turbidimetric measurement (19) and colorimetric assay $(20)$, respectively. Isotachophoretic results were plotted against the results of the routine methods, and the sets of data were statistically evaluated by orthogonal regression, -calculation of correla- 
tion and by the procedure of Passing \& Bablock (21). The characteristics of the straight lines (slope, intercept) are well within the confidence limits for the methods. The straight lines obtained for the three statistical methods practically coincide. The frequency ellipses in the figures represent the $95 \%$ probability limit of the calculated correlations.

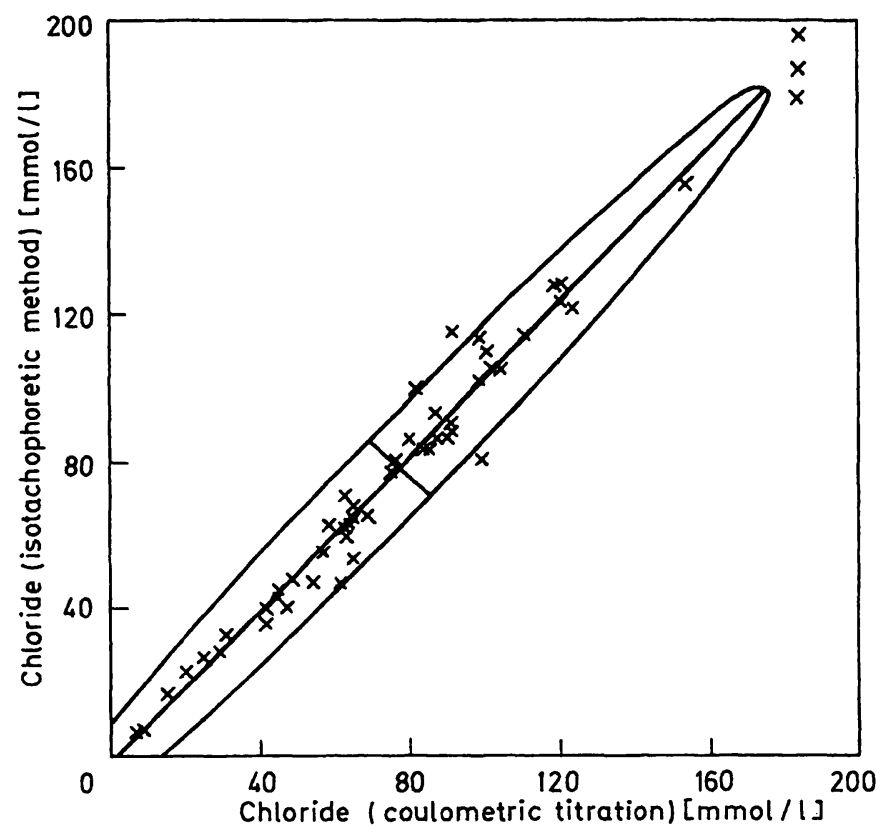

Fig. 4. Correlation between present method and coulometric titration assay for determination of chloride in 55 urine samples.

$r$ : Correlation coefficient, $r=0.99$

B: Coefficient of determination $\left(B=r^{2}\right), B=0.98$

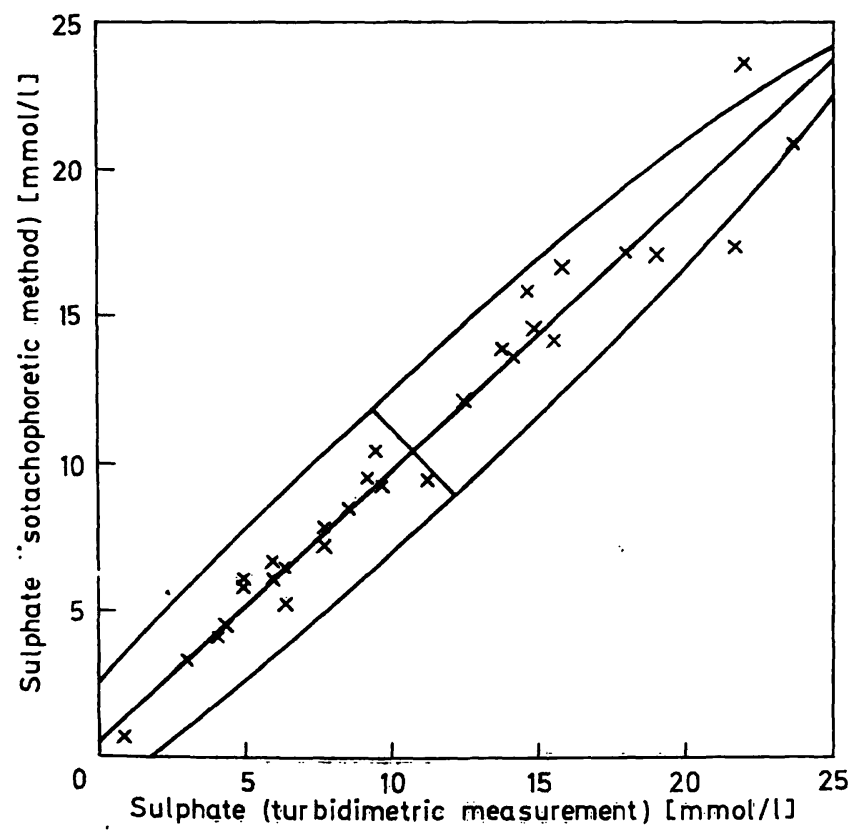

Fig. 5. Correlation between present method and turbidimetric measurement assay for determination of sulphate in $\mathbf{3 0}$ urine sạmples.

$\mathrm{r}=0.98 ; \mathrm{B}=0.96$
Tab. 3. Analytical recovery of chloride, sulphate and orthophosphate from pooled urine

\begin{tabular}{lllll}
\hline Anion & Added & Measured & $\begin{array}{l}\text { Theoret- } \\
\text { ical } \\
(\mathrm{mmol} / \mathrm{l})\end{array}$ & $\begin{array}{l}\text { Recovery } \\
(\%)\end{array}$ \\
\hline Chloride & 0 & 35.20 & - & - \\
& 2.0 & 37.25 & 37.20 & 103 \\
& 4.0 & 39.00 & 39.20 & 95.0 \\
& 6.0 & 41.19 & 41.20 & 99.8 \\
& 8.0 & 43.68 & 43.20 & 106 \\
\hline Sulphate & 0 & 3.82 & - & - \\
& 2.0 & 5.83 & 5.82 & 101 \\
& 4.0 & 7.56 & 7.82 & 93.5 \\
& 6.0 & 9.57 & 9.82 & 95.8 \\
& 8.0 & 11.62 & 11.82 & 97.5 \\
\hline Orthophos- & 0 & 6.14 & - & - \\
phate & 2.0 & 8.06 & 8.14 & 96.0 \\
& 4.0 & 9.93 & 10.14 & 94.8 \\
& 6.0 & 12.07 & 12.14 & 98.8 \\
& 8.0 & 13.93 & 14.14 & 94.4 \\
\hline
\end{tabular}

Numerically the results obtained can be summarized as follows:

\begin{tabular}{lcrrl}
\hline & $\mathrm{n}$ & slope & $\begin{array}{r}\text { intercept } \\
(\mathrm{mmol} / \mathrm{l})\end{array}$ & $\begin{array}{l}\text { correlation } \\
\text { coefficient }\end{array}$ \\
\hline Chloride & 55 & 1.024 & -0.110 & 0.988 \\
Sulphate & 30 & 0.912 & 0.660 & 0.981 \\
Orthophosphate & 48 & 0.965 & 0.618 & 0.987 \\
\hline
\end{tabular}

The isotechophoretic method therefore shows good correlation with the routine methods.

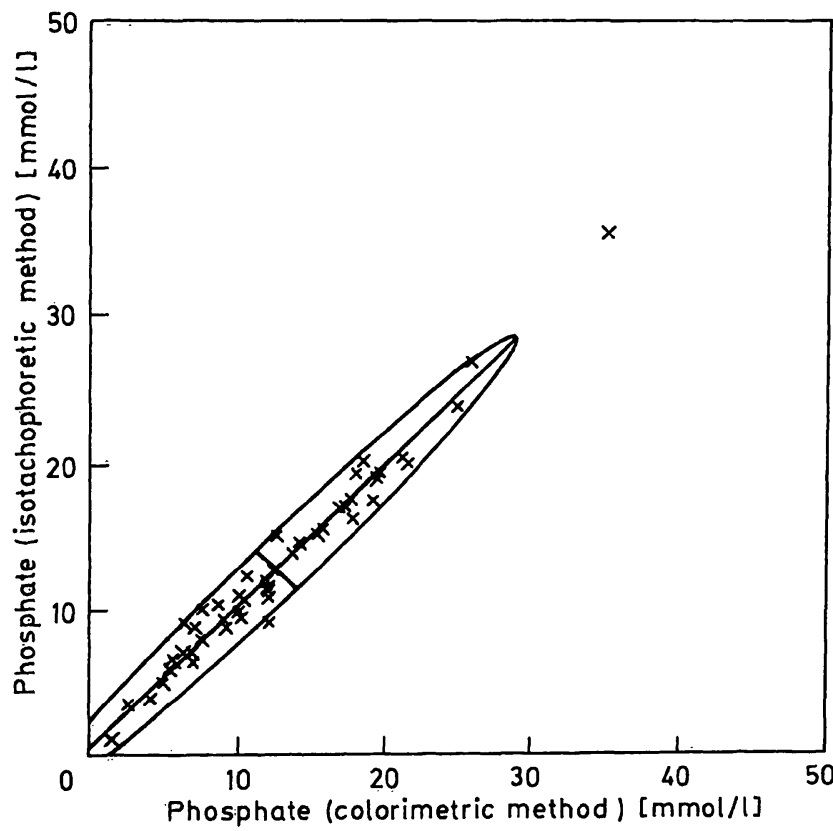

Fig. 6. Correlation between present method and colorimetric method for determination of phosphate in 48 urine samples.

$\mathrm{r}=0.99 ; \mathrm{B}=0.97$ 


\section{Discussion}

Human urine contains a number of inorganic and organic anions of which chloride, sulphate and orthophosphate are the most abundant. Inorganic anions have generally high mobilities in an isotachophoretic system. The mobilities of chloride, nitrate and sulphate are very similar in aqueous solution and these ions are difficult to separate using the generally applied operational conditions of isotachophoresis. The leading ion is chosen to have a higher mobility than all the other ionic species of interest. The literature indicates that $\mathrm{Fe}(\mathrm{CN})_{6}^{4-}$, $\mathrm{Fe}(\mathrm{CN})_{6}^{3-}, \mathrm{CrO}_{4}^{2-}$ are fast moving ions at infinite dilution, the limiting mobilities being greater than those of chloride, nitrate and sulphate. However, experiments showed that under the above conditions the mobilities of these ions used as leading electrolytes are not sufficiently different from the ions of the analyte and hence poor separation at the front results. A mixed zone between the leading ion and chloride is obtained (5). The hydroxide ion is the most mobile anion in water and can be used as a leading electrolyte. Although its high mobility would make it an excellent choice for separating all anions we could not establish suitable conditions for the use of the hydroxide ion in the specific problem of urine analysis. Also, finding a suitable leading electrolyte for the separation of chloride and sulphate presents a formidable problem. The kinetically labile complexes formed with different cations $\left(\mathrm{Ca}^{2+}, \mathrm{Cd}^{2+}, \mathrm{Al}^{3+}\right.$, $\mathrm{Cu}^{2+}$ etc.) can be used to reduce the mobility of some of the anionic species (22). Adding complex-forming counter ions to the leading electrolyte results in the formation of labile complexes of different thermodynamic stability. In this way it is possible to effectively separate chloride and sulphate ions and to estimate their concentrations. Nitrate, which does not form complexes, was chosen as the leading anion. In an aqueous system, Bocek et al. (6) separated the halides quantitatively together with sulphate, using $\mathrm{Cd}^{2+}$ as the counter ion and nitrate as the leading ion. $\mathrm{Cd}^{2+}$ as the only counter ion, however, does not yield good separations of anionic components in urine. Experimentally we found that addition of $\beta$-alanine as a second counter ion in the leading electrolyte at $\mathrm{pH}=3.0$ enhances the development of sharp boundaries and thus increases the resolution and reproducibility of the isotachophoretic procedure.

Comparison of the UV absorption recordings of the isotachopherograms of the urine samples and the standard solution clearly reveals that the urine contains other substances in small concentrations. In the standard solution, with the exception of impurities in the formate zone, practically no absorption is detected between different zones. The small deflections are most probably due to scattering or refraction at the boundaries. In the sample, however, large peaks indicate the presence of small amounts of highly absorbing compounds. The absorbance located between sulphate and orthophosphate may be due to small amounts of nucleotides, since ATP is known to migrate between the two fractions. Salicylate, another component normally occurring in urine samples in very small concentrations, appears between formate and citrate. Other compounds responsible for small and unresolved zones could be vanilylmandelic acid or other metabolites of the catecholamines and 5hydroxyindolacetate. In principle, it is possible to estimate anionic constituents occurring in normal urine at concentrations in the order of $10^{-4} \mathrm{~mol} / \mathrm{l}$, e. g. oxalate, pyruvate, lactate, salicylate and ascorbate. For such an analysis, however, under the same conditions a large volume of urine sample $(10 \mu$ or more) must be injected. This increases the time of analysis unduly. For the system presented here the analysis time was about 30 minutes (depending on the urine sample), whereas an analysis time of severals hours was necessary to resolve less concentrated constituents. With a ratio of $1000: 1$ between chloride (the most concentrated ion) and less abundant compounds, analysis becomes impracticable.

Although we could demonstrate the usefulness of isotachophoresis in determining some inorganic anions in urine, much remains to be done to improve the estimation of constituents present in lower concentrations. Since isotachophoresis offers the possibility, under suitable conditions, of separating and estimating all ionic species at low cost and effort (no expensive reagents, no consumables, no moving parts hence easy maintenance and no pretreatment of urine samples) it deserves certainly more attention in analytical chemistry and more particulary in clinical chemistry.

\section{Acknowledgement}

We thank Wolfgang Häfliger for his assistance in the experimental work which demanded great patience. We gratefully acknowledge the helpful discussions with Prof. E. Schumacher, Bern. 


\section{References}

1. Relman, A. S., Lennon, E. J. \& Leman, J., Jr. (1961) J. Clin. Invest. 40, 1621-1630.

2. Schwartz, W. B. \& Jenson, R. L. (1958) J. Clin. Invest. 34, $673-680$.

3. Seldin, D. W., Coleman, A. J., Carter, N. W. \& Rector, F. C., Jr. (1967) J. Lab. Clin. Med. 69, 893-903.

4. Schumacher, E., Thormann, W. \& Arn, D. (1981) A new approach to automated isotachophoresis with multichannel zone detection. Analytical Chemistry Symposia Series 6, 33-39.

5. Everaets, F. M., Becker, J. L. \& Verheggen, Th. P. E. M. (1976) Isotachophoresis (Theory, Instrumentation and Applications). J. Chromatography Library 6, 295-310.

6. Bocek, P., Miedziak, I., Deml, M. \& Janak, J. (1977) J. Chromatogr. 137, 83-91.

7. Schwendtner, N., Achilles, W., Engelhardt, E., Schwille, P. O. \& Sigel, A. (1982) J. Clin. Chem. Clin. Biochem. 20, $833-836$.

8. Tschöpe, W. \& Ritz, E. (1980) J. Chromatogr. 221, 59-65.

9. Tschöpe, W. \& Ritz, E. (1981) Simultaneous Measurement of Oxalate and Citrate in Unprocessed Urine with Isotachophoresis - Clinical Application. In: Analytical Isotachophoresis (Everaets, F. M., ed.) Elsevier, Amsterdam, pp. 63-68.

10. Van der Hoeven, J. S. \& Franken, H. C. M. (1980) The Determination of Various Low-Molecular-Weight Carboxylic Acids in Biological Samples by Isotachophoresis. In: Biochemical and Biological Applications of Isotachophoresis (Adam, A. \& Schots, C., eds.) Elsevier, Amsterdam, pp. $69-79$.
11. Oberrittner, H., Bruchelt, G. \& Schmidt, K. H. (1984) Quantitative Determination of Ascorbic Acid in Biological Material by Isotachophoresis. In: Analytical and Preparative Isotachophoresis (Holloway, C. J., ed.), Walter de Gruyter, Berlin, New York, pp. 237-242.

12. Mikkers, F., Ringoir, S. \& De Smet, R. (1979) J. Chromatogr. $162,341-350$.

13. Dogan, S. \& Haerdi, W. (1981) Chimia 35, 339-342.

14. Darimont, T., Schultze, G. \& Sonneborn, M. (1983) Fresenius Z. Anal. Chem. 314, 383-385.

15. Anderson, C. (1976) Clin. Chem. 22, 1424-1426.

16. Menon, M. \& Mahle, C. J. (1983) Clin. Chem. 29, $369-371$.

17. De Jong, P. \& Burggraaf, M. (1983) Clin. Chim. Acta 132, 63-71.

18. Seligson, D. (1961) Standard methods of clinical chemistry. Academic Press, New York and London 3, 81-92.

19. Lundquist, P. \& Martenson, J. (1980) Clin. Chem. 26, $1178-1181$.

20. Merckotest 3331, Inorganic Phosphorus, Colorimetric Determination (method without deproteinization).

21. Passing, H. \& Bablock, W. (1983) J. Clin. Chem. Clin. Biochem. 21, 709-720 and (1984) J. Clin. Chem. Clin. Biochem. 22, $431-445$.

22. Kamiansky, D. \& Everaerts, F. M. (1978) J. Chromatogr. $148,441-446$.

Prof. D̀r. D. J. Vonderschmitt

Klin.-Chem. Zentrallaboratorium

Universitätsspital

CH-8091 Zurich 

J. Clin. Chem. Clin. Biochem.

Vol. 25,1987 , pp. $261-264$

(C) 1987 Walter de Gruyter \& Co. Berlin - New York

\title{
Filter Paper Blood Sampling for Glycated Haemoglobin Determination and its Use in the Control of Diabetes Mellitus
}

\author{
By Elizabeta Topić \\ Institute for Clinical Laboratory Diagnostics, Clinical Hospital Centre, School of Medicine, \\ University of Zagreb, Zagreb, Yugoslavia
}

Renata Zadro, M. Granić and Z. Škrabalo

Vuk Vrhovac Institute of Diabetes, Endocrinology and Metabolic Diseases, Ozren Novosel Clinical Hospital, School of Medicine, University of Zagreb, Zagreb, Yugoslavia

(Received July 3/October 10, 1986/January 28, 1987)

Summary: Blood sampling on filter paper was tested for determination of glycated haemoglobin. The method showed coefficients of variation of $3.4 \%$ and $4.1 \%$, and linearity coefficients of 0.978 and 0.91 for the microchromatographic and colorimetric methods respectively. A blood sample on filter paper impregnated with $5 \%$ ethylene glycol solution remains stable for 8 days at room temperature.

In a group of 30 diabetics educated in the filter paper blood sampling technique, no statistically significant differences were registered among the mean values of their blood glucose profiles, glycated haemoglobin levels determined at the hospital and those obtained at home 14 days after discharge.

In conclusion, the use of blood spotted on filter paper seems a cheap and convenient method for collecting, storing and transporting samples for analysis of glycated haemoglobins. It is also a useful alternative for home monitoring of diabetics. Moreover, it could also be useful in epidemiological studies of diabetes.

\section{Introduction .}

Glycated haemoglobin is generally considered to be a valuable biological criterion reflecting the assessment of glycaemia in diabetics during the past two to three months. Its quantification is routinely included in both the control and diagnosis of diabetes mellitus $(1-5)$.

Moreover, the WHO Expert Committee on Diabetes Mellitus has recommended that glycated haemoglobin be determined every time that a patient visits a diabetic clinic, because the severity of diabetes is most probably better reflected by this parameter than by the glucose measurement alone (6).
As many diabetics live far from the centres where glucose and even glycated haemoglobin can be determined, an attempt was made to develop a method for the measurement of glycated haemoglobin which would eliminate long, costly and inconvenient journeys to distant centres, which often discourage patients to report for check-ups. For this purpose, blood was collected on filter paper, and the analytical results were compared with those obtained from blood collected in tubes. The practical application of the filter paper blood sampling technique for the home monitoring of diabetics was also studied.

\section{Methods}

The technique of filter paper blood sampling

Whatman No. 3 filter papers $(4 \times 10 \mathrm{~cm})$ were pretreated by impregnation with $15 \%$ ethylene glycol solution, $\mathrm{pH} 6.5$ (Kemika, Zagreb, YU). Samples of whole blood (150 $\mu \mathrm{l})$ were applied to the filter paper and allowed to dry. Before analysis, the blood was eluted from the filter paper with $200 \mu \mathrm{l}$ of haemolyzing solution ( $3 \mathrm{~g} / \mathrm{l}$ saponin, $1 \mathrm{~g} / \mathrm{l}$ EDTA, Kemika, Zagreb, YU) and an aliquot of the eluate was used for glycated haemoglobin determination.

\section{Methods for glycated haemoglobin determination}

Glycated haemoglobin was determined by a modified chromatographic method of Trivelli (7) on microcolumn (Panchem, Kleinwallstadt, FRG) and by Winterhalter's colorimetric method (8) modified at the haemolysis stage (9). The normal range in our population for the fraction of glycated Hb determined by the microchromatographic method is $0.056-0.086$. 
The normal range determined by the colorimetric method can be expressed as an hydroxymethylfurfural value of 394-518 $\mathrm{nmol} / \mathrm{g} \mathrm{Hb}$. The coefficients of correlation for both methods were less than $3.3 \%$.

\section{Subjects}

Blood was collected from 55 male and 47 female diabetics aged 20-55 years, mean 30.5 years, and 63 healthy volunteers of both sexes, mean age 32 years.

\section{Quality control materials}

A large aliquot of the patient's haemolysate, prepared by haemolysis with $3 \mathrm{~g} / \mathrm{l}$ of saponin and $1 \mathrm{~g} / \mathrm{l}$ of EDTA, was mixed with ethylene glycol $(5 \%)$. The homogeneity of this mixture was studied by 20 consecutive determinations of glycated haemoglobin levels in the samples obtained from both normal and diabetic subjects, using the chromatographic and colorimetric methods. Small aliquots of the control material were kept at various temperatures (room temperature, $+4{ }^{\circ} \mathrm{C}$ and $-20^{\circ} \mathrm{C}$ ) and the stability of glycated haemoglobin was measured daily. Before determination, each control vial was warmed up to room temperature.

\section{Results}

Comparison of glycated haemoglobin values obtained by measurements of filter paper and tube blood samples

The glycated haemoglobin values obtained by the chromatographic and colorimetric methods for both the filter paper and tube samples show a high correlation (fig. 1), suggesting the results of filter paper sampling are almost identical to those sampled in the usual way.

Twenty consecutive chromatographic determinations in blood samples eluted from the filter paper on the day of sampling showed a coefficient of variation of $3.4 \%$; the assays were performed one hour after elution of the haemolysate from the filter paper, using the haemolyzing solution containing aldimine eliminator (Panchem, Kleinwallstadt, FRG). For the colorimetric method, the coefficient of variation was $4.3 \%$.

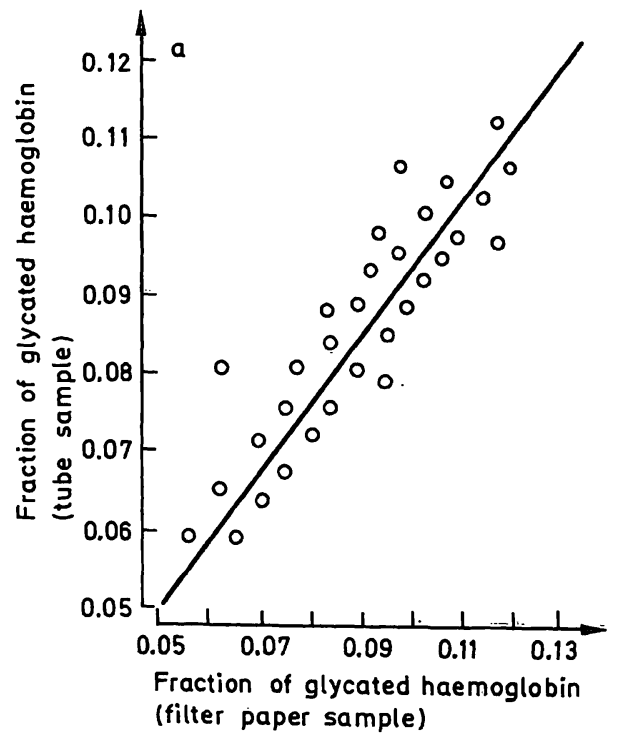

\section{Homogeneity and stability of quality control material}

The intra-assay reproducibility in ethylene glycol control material by the microchromatographic method was $3.8 \%$ and $3.9 \%$ for normal and diabetic haemolysate respectively. In the colorimetric method, the coefficient of variation was $4.2 \%$ for normal and $4.5 \%$ for diabetic haemolysates. These results suggest a quite satisfactory reproducibility and homogeneity of quality control material, regardless of the methpd used. Ethylene glycol control haemolysate was found to be stable for 8 days at room temperature, 16 days at $+4{ }^{\circ} \mathrm{C}$ and more than 90 days at $-20^{\circ} \mathrm{C}$. These results suggest that the control haemolysate prepared as above and stored in an appropriate manner could serve as a stable control material over several months.

\section{Stability of the filter paper sample}

The filter paper was impregnated for 5 hours with $15 \%$ ethylene glycol solution, and dried overnight. Forty blood samples were applied to it, dried and stored at room temperature. Three sample blood spots on the filter paper were used in the test procedure every day. The mean values, presented in rigure 2, show that glycated haemoglobin in the filter paper blood sample, impregnated with ethylene glycol solution, remains stable for 8 days at room temperature. This is long enough to allow long distance transportation to the laboratory.

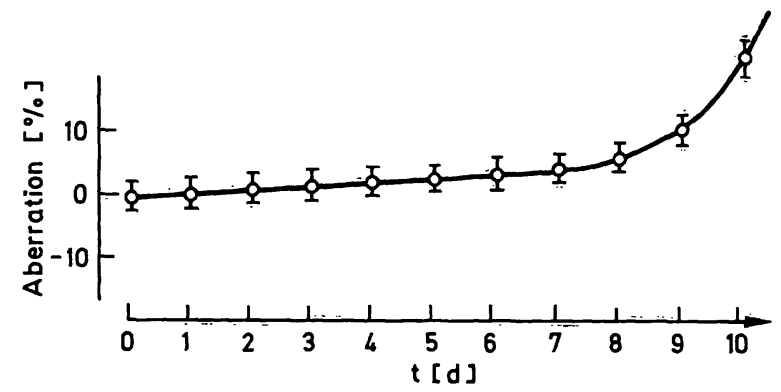

Fig. 2. Stability of glycated haemoglobin in blood samples on filter paper impregnated with ethylene glycol solution. The starting value $(100 \%)$ corresponds to the aberration $0 \%$.

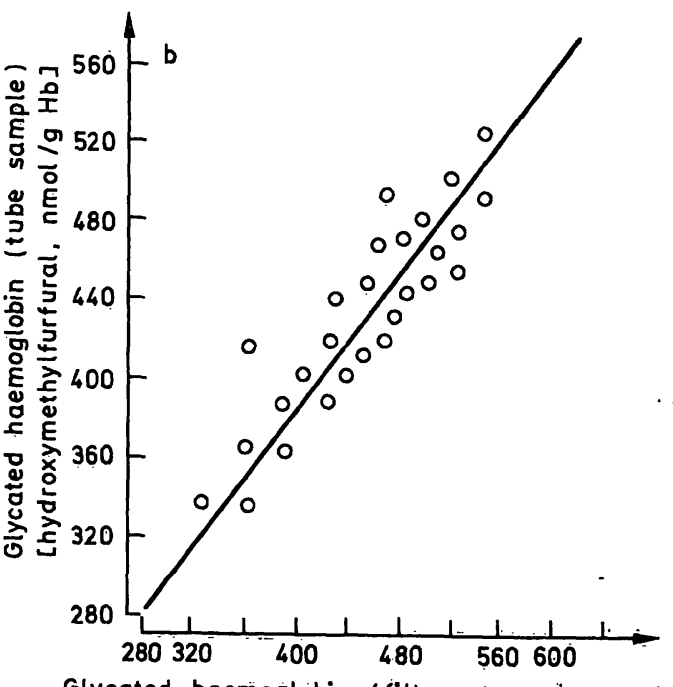

Glycated haemoglobin (filter paper 'sample) [hydroxymethylfurfural, $\mathrm{nmol} / \mathrm{g} \mathrm{Hb}$ ]

Fig. 1. Correlation of glycated haemoglobin values from haemolysate in tube (y) and on filter paper $(x)$

a) microcolumn method, $r=0.978 ; p<0.001$

b) colorimetric method, $\mathrm{r}=0.91 ; \mathrm{p}<0.001$ 
The high correlation between the tube and filter paper blood samples, and the reproducibility and stability of the filter paper samples show that this method guarantees results of the same value as those obtained from samples collected in the conventional way.

The application of the filter paper blood sampling technique in patient home monitoring

This sampling technique was studied in 30 diabetic patients with a stable type of diabetes who had been treated at the Clinic and lived in remote localities. All the patients were instructed in the use of the filter paper sampling technique.

During hospitalization, the blood glucose profile and glycated haemoglobin were determined in the samples collected in the usual way. Before the patient was discharged, the study plan was explained, and he was given filter papers impregnated with ethylene glycol. Each filter paper was marked with a $20 \mathrm{~mm}$ diameter circle. The patient was instructed to do a daily blood glucose profile consisting of seven measurements 14 days after he had left the hospital. At the same time when taking his first blood for the profile, he was supposed to take a sample on filter paper and send it to us within the next two days.

Although the patients lived at different distances, all the filter paper blood samples and glucose profile results reached us within 5 days. The results were compared to those obtained in the hospital and statistically analysed.

The mean blood glucose profiles determined at the hospital and at home were $8.13 \pm 4.60 \mathrm{mmol} / \mathrm{l}$ and $8.83 \pm 5.30 \mathrm{mmol} / \mathrm{l}$ respectively. The difference was statistically insignificant $(p>$ 0.05). Concerning the aim of the study, it was more important that neither the differences between the glycated haemoglobin values measured at the hospital and those from the filter paper blood were statistically significant $(p>0.05)$. Thus, the mean glycated haemoglobin given as hydroxymethylfurfural value was $420 \pm 56 \mathrm{nmol} / \mathrm{g} \mathrm{Hb}$ and $468 \pm 86 \mathrm{nmol} / \mathrm{g} \mathrm{Hb}$ at the hospital and at home respectively both measured by the colorimetric method. The comparability of the results obtained by the two blood sampling techniques was also supported by the high coefficient of correlation $(r=0.815)$.

\section{Discussion}

Regardless of the method used for glycated haemoglobin determination, only a high precision and accuracy can guarantee on optimal clinical usefulness. As glycated haemoglobin is an indirect measure of the mean glucose concentration each 0.01 difference in measured fraction of glycated haemoglobin level represents a change of about $35 \%$ in blood glucose level (10). A measurement technique is therefore required that is capable of distinguishing small glycated haemoglobin changes with a variation coefficient lower than $5 \%$. The current problem in optimizing these analyses is still the availability of suitable control material for the glycated haemoglobin assay. An ethylene glycol-stabilized haemolysate for use as control material is described by Mosca et al. (11). This control material shows satisfactory long-term stability. Our own prepared ethylene glycol control material also shows good homogeneity and stability, suggesting that it could be used in every day quality control.

Filter paper blood sampling for glycated haemoglobin determination is reproducible and precise with a variation coefficient of $3.4 \%$ and $4.1 \%$ and a linearity coefficient of 0.978 and 0.91 for the microchromatographic and colorimetric methods, respectively.

A blood sample on the filter paper impregnated in ethylene glycol solution remains stable for 8 days, allowing long distance transport from any place to the nearest laboratory equipped for glycated haemoglobin measurements.

Determination of glycated protein in blood sampled on filter paper was recently described (12), but in that method it was necessary to measure glucose in the prepared haemolysate, in order to correct the final glycated protein value, since both these values seem to increase with time.

Our results for glycated haemoglobin stability on the filter paper without impregnation by ethylene glycol solution also showed increasing values, although the blood was dried.

It is worth mentioning that the glycated haemoglobin concentration increases in both methods. In order to preserve the blood, the filter paper was impregnated with various blood preserving solutions commonly used in the clinical laboratory (sodium azide, boric acid, merthiolate and EDTA) for two hours, but stability ẁas not satisfactory.

From the analysis of our data we concluded that, although the sample on filter paper was completely dry, continuous denaturation of total haemoglobin was not prevented, causing a decrease in the total haemoglobin concentrations, which turn resulted in falsely high glycated haemoglobin values. The haemoglobin value acts as the basis for calculation of the glycated haemoglobin concentration, which therefore appeared to be higher than it actually was. Finally, the blood sample on the filter paper impregnated with $15 \%$ of ethylene glycol solution gave satisfactory stability.

The use of ethylene glycol as a matrix for the control sample is not new $(13,14)$ and our findings extend its application.

A well motivated patient can collect his blood on filter paper and provide his physician with reliable data on diabetic control.

The main aim of this study seems to be achieved: the patients do not need to travel a long way for their check-ups at distant diabetic clinics. They can simply mail their filter paper samples for analysis 3-4 times a year.

Considering the potential of this technique, one might also consider its use in the epidemiology of diabetes.

\section{Acknowledgement}

We wish to thank the firm of Panchem for their gift of microcolumns, and the Research Foundation of Croatia (SIZ-V) for their financial support.

\section{References}

1. Bunn, H. F., Gabbay, K. H. \& Gallop, P. M. (1978) Science $200,21-47$.

2. Gabbay, K. H. (1976) N. Engl. J. Med. 259, 443-454.

3. Gabbay, K. H., Hasty, K., Breslow, J. L., Ellison, R.C., Bunn, H. F. \& Gallop, P. M. (1977) J. Clin. Endocrinol. Metab. 44, 859-864.

4. Bunn, H. F. (1981) Diabetes 30, 613-617.

5. Topić, E. (1980) Diab. Croat. 9, 351-380.

6. WHO Expert Committee on Diabetes Mellitus Report (1985) WHO TRS No. 727, WHO, Geneva.

7. Trivelli, L. A., Ranney, H. M. \& Lay, H. T. (1971) N. Engl. J. Med. 284, 353-357. 
8. Flückiger, R. \& Winterhalter, K. (1976) FEBS Lett. 71, $356-360$.

9. Zadro, R. \& Topić, E. (1985) Diab. Croat. 14, 219-226.

10. National Diabetes Data Group: Report of the Expert Committee on Glycated Haemoglobin, Diab. Care (1984) 7, 602-606.

11. Mosca, A., Carpinelli, A., Paleari, R., Carenin, A., Bonini, P. \& Franzini, C. (1985) J. Clin. Chem. Clin. Biochem. 23, $361-364$.
12. Goldstein, D. E., Wiedmeyer, H. M., England, J. D., Little, R. R. \& Parker, K. M. (1982) Clin. Chem. 28, 386-387.

13. Pope, V. T., Caragher, T. E. \& Grannis, G. F. (1979) Clin. Chem. 25, 413 - 418 .

14. Grannis, G. F. \& Miller, W. G. (1976) Clin. Chem. 22 $500-512$.

Elizabeta Topić, Ph. D.' '

Institute for Clinical Laboratory Diagnostics Clinical Hospital Centre, School of Medicine University of Zagreb

Kišpatićeva 12

YƯ-41000 Zagreb 